\title{
Theistic Percepts in Other Species: Can Chimpanzees Represent the Minds of Non-Natural Agents?*
}

\author{
JESSE M. BERING**
}

\begin{abstract}
The present theoretical article addresses the empirical question of whether other species, particularly chimpanzees, have the cognitive substrate necessary for experiencing theistic and otherwise non-natural (i.e., non-physical) percepts. The primary representational device presumed to underlie religious cognition was viewed as, in general, the capacity to attribute unobservable causal mechanisms to ostensible output and, in particular, a theory of mind. Drawing from a catalogue of behaviors that may be considered diagnostic of the secondary representations involved in theory of mind (or at least theory of mind precursors), important dissimilarities between humans and other species in the realms of the animate-inanimate distinction (self-propelledness versus mental agency of animate beings), imaginative play (feature-dependent make-believe versus true symbolic play), and the death concept (biological death conceptualization versus psychological death conceptualization) were shown. Differences in these domains support the claim that humans alone possess the foundational and functional representations inherent in religious experiences.
\end{abstract}

\section{KEYWORDS}

Theory of mind, theism, religious cognition, chimpanzees, animism, symbolic play, death concept.

*I am indebted to David Bjorklund, with whom many of the ideas presented in this paper were discussed and developed. I also thank Justin Barrett, Jennifer Yunger, Patricia Ragan, Todd Shackelford, Gordon Gallup, Maxx Carroll, Asif Ghazanfar, Siân Evans, and an anonymous reviewer for valuable comments.

** Department of Psychology, Florida Atlantic University and The Center for Orangutan and Chimpanzee Conservation. Address correspondence to: Jesse M. Bering, e-mail: jber4317@fau.edu 


\title{
Theistic Percepts in Other Species: Can Chimpanzees Represent the Minds of Non-Natural Agents?
}

\author{
"God is an inhuman concept."
}

Friedrich Dürrenmatt

The past decade has seen a unique fusion of the two otherwise encapsulated academic domains of comparative religion and human cognition. While it may strike the uninitiated as an unlikely marriage, even a casual reading in this area will show that it already has been extremely fruitful; its success bears witness to the benefits of applying cognitive theory to independent areas of scholarly research. Religion is no longer, it seems, immune to the explanatory power of modern science - the concept of "sacredness" is becoming delimited to scientific methodology, at least among some religious and biological investigators.

At the forefront of this synthesis are a few standout theorists, who early on recognized that the ubiquity of the foundational and functional levels of religious behavior, such as ancestor and theistic worship, interphenomenalistic dialogue (e.g., prayer), and 'First Cause' theorizing, might be dependent upon shared cognitive universals (e.g., J. Barrett \& Keil 1996; Boyer 1994, 1999; Guthrie 1993; Hinde 1999; Lawson \& McCauley 1990; for review see J. Barrett 2000). While the particulars may vary (often tremendously) between religious systems, the supporting ontologies are strikingly similar. The range of ecumenical machines was likely born only after populations became segregated and societies evolved their own unique religious institutions.

Examining the evolutionary origins of religion has prompted some researchers (e.g., Boyer 1999) to suggest that one core ontological unit, theory of mind, is the most important component of theistic conceptions. It is difficult, if not impossible, to imagine a vegetative, autistic, or otherwise "mindblind" deity who is duly worshipped by his or her followers, nor can one easily conceive of a worshipper who exhibits these cognitive impairments. ${ }^{1}$ The problem with such a task is that the relationship is

${ }^{1}$ While it is true some autists engage in religious activities, often compulsively, their motivations for doing so may be quite different from those of a cognitively normal individual. Temple Grandin, a scientist and autist herself, writes, "There are autistic people who adopt very fundamentalist beliefs and become obsessed with religion. One girl prayed 
a highly social one (see Burkert, 1996) and therefore any religious behavior emitted by the worshipper that taps into the perceived interplay between the two is necessarily dependent upon the normal cognitive underpinnings of human social intelligence. To intentionally attempt to communicate a message to a non-natural (i.e., non-physical) agent presupposes that the worshipper represents it as a potentially receptive social partner. Prayer, complex rituals and libation, sacrificial offerings and other forms of religious supplication depend on the imagined social cognitive skills of the attendant gods. In short, gods must have minds to be gods.

\section{Do Other Species Possess the Cognitive Hardware Needed for Theism?}

Theory of mind, therefore, has not surprisingly been described as playing a pivotal role in the origins of religion (e.g., Baron-Cohen 1999; Boyer 1999). Yet an important question remains unanswered and, indeed, has not even received due speculation, 'Can other organisms experience theistic percepts.' Among the religious laity, gut responses to the query will probably range from the non-reflective churchgoer's, "Of course not!" to the philosophical reverend's, "Of course!" But the question is far from a simple one, and though informed intuitions may lead even scientists to answer confidently in the negative, the answer is likely tied to the contentious debate over whether nonhuman primates possess a theory of mind - and the dust from that scientific scuffle is cloudier than ever.

The importance of the question is two-fold. First, getting at the phyletic origins of "hardwired" concepts such as those envisioned to be active in religious behaviors can reveal whether great apes possess the representational structure to entertain notions of non-natural agents. Second, such information can inform us of the evolutionary pathways of religious thinking. If such an intuitive ontology is absent in chimpanzees, then theism probably occurred at some point after hominids diverged from

for hours and went to church every day. In her case it was an obsession instead of a belief, and she was kicked out of several churches" (1995; p. 190). Religious behaviors in autists, it seems, have much in common with other non-functional behaviors associated with the disorder, such as stereotypic rocking or hand-rubbing. Further research on the religious representations of autistic patients is greatly needed and could contribute immensely to the theism-theory of mind hypothesis. 
the rest of the primate lineage - somewhere between 5 mya and as late as 60,000 ya. Surely it is an onerous problem, but it does deserve a closer look.

Maser and Gallup (1990) provided the first theoretical treatment of the question, suggesting the intriguing possibility that chimpanzees may possess the rudimentary requirements for theism. Drawing from findings of Gallup's (1970) dye mark mirror self-recognition test, in which chimpanzees, but not macaque monkeys, readily passed, the authors argue that chimpanzees possess the attributional self-awareness necessary for at least the basic representations involved in theism. They maintain, however, that although chimpanzees have a theory of mind, this in itself is a necessary but not sufficient condition for theism. "We would predict that, if chimpanzees could be taught to understand their own impending death, if they understood existential terror, then the notion of God might become a more central and maintained concept" (Maser \& Gallup 1990, p. 526). According to this argument, then, without understanding (and fearing) personal death, there is no reason to have a God concept. Whether and what apes understand about death is not well-understood and will be discussed in more detail below, but a potential problem with the theory is that theistic percepts are viewed as imposed to quell learned death anxiety. It ignores the integrative role of intuitive ontological units in generating natural theistic concepts and instead implicates human defense mechanisms as the presiding causal force. Theism, while perhaps mediated at least in part by emotional cues, certainly plays a role in everyday matters that are not directly related to death. For example, social psychologists have shown that supernatural attributions are often triggered by fairly precise and identifiable conditions, such as when religious individuals explain lifealtering occurrences with a favorable outcome as being distally caused by God (Lupfer, Tolliver \& Jackson 1996). We should be wary of any arguments that claim gods are an unconscious human invention ( $c f$. Freud 1927). Rather, humans (at least) to an extent come into the world with gods already on the brain.

To be sure, certain readers will recoil at this claim because it seems to neglect the fact that there are many individuals who are quite confidently agnostic or atheistic, and who do not regularly entertain notions of nonnatural causality. However, I take these affiliations to be surface theoretical 
positions against core, cognitively constrained attributional styles. They have arisen via a metarepresentational system allowing humans to reflect upon their core concepts, whereby the two extremes of belief and disbelief in deities involve an elaboration and a rejection of an intuitive ontology, respectively. This model may be envisaged to be roughly analogous to some "theory" theories, in which specific theories are generated from various learning processes and become embedded in foundational theories to account for concepts in core domains (see Gopnik \& Meltzoff 1997).

Since Gallup's seminal work with chimpanzees, a number of plausible arguments have been launched against his initial conclusion that mirror self-recognition is diagnostic of theory of mind (see Mitchell 1993). In general, experimental work is beginning to show that chimpanzees might not be as self-aware as once thought. Indeed, a sizeable minority of comparative scientists (e.g., Povinelli \& Preuss 1995; Tomasello 1999) recently has argued that theory of mind is a human cognitive specialization. However, most others (e.g., see Byrne \& Whiten 1990; Boesch 1991; Gómez \& Teixidor 1992) ${ }^{2}$ still hold fast to the notion that other primates, namely great apes, can attribute — albeit minimally — mental states including intentions, beliefs, and desires to themselves and others.

While a thorough coverage of the jungle of relevant literature is beyond the purview of the present article, a closer look at how apes represent the natural world might be particularly useful in trying to uncover whether they have any semblance of religious percepts. Among the most important areas to address, I believe, are the following: the animate-inanimate distinction, imaginative play, and the death concept. While they should certainly not be regarded as directly causative of theistic percepts, each of these categories seems to involve the foundational secondary representations involved in human religious activity and therefore serves to illuminate critical religious cognitive mechanisms.

\footnotetext{
${ }^{2}$ The cited authors have argued that great apes can engage in intentional teaching of naïve conspecifics, adopt the perspective of others in order to deceive them, and intentionally communicate the location of hidden objects (by declarative pointing) to ignorant humans, respectively.
} 


\section{Killer Leaves and Friendly Leaves: Other Species' Ability to Discern the Attributes of the Living}

In order to conceive of a grand causal engineer in the universe who willfully employs its omnipotence to communicate its intentions via indirect symbolic means, an organism must first be able to represent the notion of intentional agency. The psychiatrist Thomas Szasz's (1973) apt statement, "If you talk to God, you are praying; if God talks to you, you have schizophrenia," is true only in a narrow sense. While gods may not actually "talk" to (most) people, they are still perceived as highly communicative agents; to the worshipper, the hurricane delaying the young couple's church wedding is not just a bad storm, but God's message to that couple to reconsider their spiritual union.

Artificial-intelligence arguments not withstanding, in the ecological sphere only animate beings can be intentional agents and only inanimate objects, due to their apperception, can be used as cognitively nonresponsive instruments. Thus the question of whether other species make this distinction is a crucial one for a search of theistic origins.

Beginning with Piaget (1929), developmental psychologists have long been interested in how young children reason about animate and inanimate objects. Researchers have found striking evidence of a natural - perhaps implicit - understanding of the causal mechanisms involved in generating movement in both categories even in very young children (Gergely 1995; Golinkoff \& Harding 1980). While there is substantial disagreement about the nature of this understanding (see Au \& Romo, 1999) there is a consensus that by middle childhood, at least, humans harbor fairly sophisticated conceptions about the nature of causality in animate beings and inanimate objects, attributing not only self-generated, directed movement to the former, but also higher-order intentions, beliefs, and desires.

Other primates, too, might have a natural understanding of some perceptual set of causal properties of animate versus inanimate objects (Hauser 1998). Because nonhuman ancestral environments included a variegated host of walking, running, flying, hopping, and crawling organisms, it is reasonable to assume that nonhuman primates did evolve some implicit "theory" of self-generated, directed movement in animate objects. In addition, there is some reason to believe that chimpanzees hierarchi- 
cally arrange other species in terms of taxonomic complexity in a manner homologous with humans (Brown and Boysen, 2000). This does not tell us, however, whether humans and chimpanzees represent the underlying causal nature of these stimuli in like manner. Indeed, work with Williams syndrome children has shown that it is quite possible to acquire rather sophisticated semantic knowledge of biological features such as whether animals have hearts or breathe, but at the same time fail to conceptualize life as a distinct causal force (Johnson \& Carey 1998). Similar paradoxes are not uncommon among chimpanzees, particularly (and most importantly) in the realm of social cognition. Evidence suggests a likely dissociation in the chimpanzee mind between attending toward social agents in a mental-like fashion and actually understanding such behaviors in mentalistic terms.

For instance, it seems that chimpanzees, like many other animals, are sensitive to feature cues of animacy such as eyes, but in addition - and unlike other animals - they also adjust their own gaze to detect the object of others' perception. It is not so obvious, however, that gaze-following is anything more than a highly adaptive exploitation of the trajectorylike projections of others' eyes. Although chimpanzees can learn to use such socially gathered information about the surrounding environment to their advantage (e.g., when a colobus monkey is scurrying in the canopy overhead) and to use their own gaze to affect the behavior of other agents, only in humans, and even then perhaps only rarely, does the sophisticated notion of seeing appear to be understood in mentalistic terms (e.g., "she is looking at the ceiling because she thinks that she sees something unusual crawling around in the air vent"). In a series of carefully controlled experiments, Povinelli \& Eddy (1996), for example, showed that a group of young captive chimpanzees selected at random between an experimenter with a blindfold covering her eyes and an experimenter who could see them when the apes solicited out-of-reach food rewards, but selected the experimenter who could see them when the choice was between a person who had her back turned and one who was facing them. Thus, the authors argue that chimpanzees probably do not attribute the mental state of "seeing" when they deploy their gestures in front of others, but rather rely on the gross behavioral configuration of the communicative partner, such as whether her frontal aspect is visible (Povinelli \& Eddy, 1996). Recent empirical work simulating more natural social conditions to get at 
the question of what chimpanzees understand about the mental state of seeing has shown that they might, in fact, understand something about the perceptual connectedness of conspecifics to the outside world (e.g., Hare, Call, Agnetta \& Tomasello 2000), but there is still a paucity of evidence that should lead us to believe that they can attribute anything like intentions, knowledge and beliefs to others.

This does not, however, undermine chimpanzee intelligence; they are highly social organisms with large brains, flexible cognitive strategies, and highly efficient learning mechanisms. These traits might have driven chimpanzees to evolve extreme sensitivities to the behavioral nuances of others, such as visual and postural orientation, and an understanding of the implications that these behaviors have for the self, such as whether a dominant conspecific's eye gaze directed toward the self's food is a good or bad thing. While such a system would clearly enhance the organism's ability to thrive in a complicated social network by allowing it to predict the behaviors of others, this should not imply that chimpanzees perceive others as anything other than animate, directed beings (Tomasello \& Call 1997). A related topic of interest to primatologists, of course, is the claim that chimpanzees and some Old World monkey species are capable of deception (and, in some cases, counter-deception) (Byrne \& Whiten 1990), but only a few of the anecdotal cases that have been reported could not be judiciously explained by alternative behavioral models.

In general, researchers must demonstrate caution in explaining other species' responses to social stimuli. Povinelli, Bering, and Giambrone (2000) have addressed the inherent problems associated with a dependence upon an argument by analogy. Originally advanced by the early comparative psychologist George Romanes (1883), the argument pushes Darwin's model of mental continuity by stressing that any differences between closely related species in terms of psychological prowess is a function of quantitative and not qualitative differences. However, we cannot be certain that similar — or even identical — behaviors in closely related species reflect isomorphic cognitive mechanisms. By evolving a qualitatively unique cognitive system allowing for mental representation of mental representations, humans might conceptualize such behaviors at more complex levels of awareness. It is not apparent that other species possess this metarepresentational capacity. 
To illustrate, some researchers have argued that human-reared apes learn to comprehend the referential gestures of human caretakers in terms of the intentions of the gesturer (Call \& Tomasello 1994; Menzel 1974; Povinelli, Nelson \& Boysen 1990). In other words, the claim has been that apes understand that others' referential gestures (e.g., pointing) are deployed in order to convey knowledge "about" something in the environment (i.e., protodeclarative function), such as the location of some hidden food reward beneath one of several possible containers. However, more controlled experiments have shown that a leaner interpretation of these apes' cognitive strategies is probably closer to the mark. For instance, when the experimenter's hand is nearer to an incorrect container (a container that does not hold the food reward) but clearly referencing the correct container with an indexical point, chimpanzees will consistently select the incorrect container — the one merely "tagged" by the physical proximity of the experimenter's hand - while 26-month-old children excel on such trials (Povinelli et al. 1997; for review, see Povinelli, Bering \& Giambrone in press).

The behavioral dissimilarities between chimpanzees and humans might be more revealing than the similarities. It is very telling, for instance, that humans are the only meat-eating primates who prefer their prey to be dead before they partake of eating animal flesh. In contrast, red colobus monkeys often have their limbs ripped off and their faces partially eaten by predatory chimpanzees while still very much alive (see Goodall 1986). As de Waal (1996a) states, "Animals often seem to regard those who belong to another kind as merely ambulant objects" (p. 84). Such behaviors are only aversive to normal humans because of our ability to experience empathy - representation of another agent's perceived psychological states — when observing animals in pain.

But if treating other kinds of animals like insensate objects is a common occurrence among nonhuman primates, do they ever make "errors" in responding to inanimate objects as if they were alive? Guthrie (1993) points out that other species are just as liable to engage in spontaneous animism as humans. In a biologically rich environment, argues Guthrie, the evolution of a perceptual sensitivity to animate beings would be highly valuable, yielding a selection gradient that favored individuals responsive to potential predation over those who were oblivious to such valuable cues. 
It is not surprising, therefore, that horses are often "spooked" by crashing branches, young vervet monkeys display an eagle alarm at falling leaves, or that our own hearts beat a little faster when we spot a garden hose in a snake-like coil against the side of the house. Because this vigilant perception is a type of environmental awareness divorced from conscious awareness, it can best be referred to as reflexive animism. It is often accompanied by a cardiac startle response and activation of the sympathetic nervous system, a pattern that initiates the fight-or-flight behavior in instances of interspecific conflict.

If animism were reserved to only this reflexive level in humans, however, we would not hear or read of 'living oceans,' or 'cruel fate.' While it could certainly be argued that such descriptions are merely metaphorical, there is evidence to suggest that humans quite seriously over-extend animate psychological characteristics to inanimate objects and natural forces on a regular basis (e.g., Dennis 1953; Inagaki \& Hatano 1987; see also Guthrie 1993). Of import is that the attribution of intentions and desires and internal essences to nonliving categories does not similarly entail the attribution of other human characteristics, such as physiological processes or physical traits (Boyer 1999). What is occurring, then, in the case of the frustrated man who smacks his "uncooperative" computer monitor is not anthropomorphism, per se, but an extension of mind (e.g., intentional will) to the object. Totemism in some hunter-gatherer societies and the idolatry present in certain world religions similarly involves deliberately endowing objects with mental states such as beliefs, intentions, and desires, as does the emotional attachment to objects underlying some cases of sentimentality. Although the inferential process of ascribing mental states might be reflexive at a foundational level, this reflective animism, as it should be called, is not a consciously blind perceptual strategy. It can involve, rather, a very serious and persistent treatment of inanimate objects as if they were animate mental agents.

Reflexive and reflective animism encompass the two sublevel cognitive processing systems characterized by Sperber's (1997) intuitive beliefs. Intuitive beliefs, according to Sperber, are those that are "grounded in perception and in spontaneous and unconscious inference from perception" (p. 76). Thus, when we spot a sudden rush of movement out of our peripheral visual field, we spontaneously infer that another organism, perhaps a 
predator, is in our vicinity. Likewise, when we see a friend smiling, we spontaneously infer that he is in a pleasurable mood (unless he is trying to deceive us!). However, Sperber's description of intuitive beliefs does not categorically distinguish between the types of processing involved in these two examples, primarily because he is concerned only with the intuitive inferential processes involved in human cognition. But only one of these examples, of course, involves a metarepresentational component. While both cases might activate perceptual devices that take sensory data as input and deliver output based on intuitive conceptual identification of these data, only the latter involves an instantiation of unobservable causation the attribution of mental states. ${ }^{3}$

Some reported incidents of nonhuman primates' spontaneous treatment of inanimate objects pose potential problems for claims that they are unable to represent non-ostensive properties such as internal states. The cultural tradition of 'leaf-grooming,' for example, has been found at four different long-term chimpanzee observation sites (Whiten et al., 1999). Goodall (1986) first described this unusual behavior as a calm, deliberate pattern of responding to randomly picked leaves as if the leaves were social grooming partners. Similar to this, perhaps, is the phenomenon of 'stone-rubbing' among several groups of Japanese macaques (Huffman, 1984), which involves the monkeys rubbing, clacking or otherwise interacting with stones. Both leaf-grooming and stone play remain relatively rare and enigmatic behaviors, and reflective animism should not be immediately discarded as a possible corollary explanation. Only in the context of findings from other careful ethological work can we suspect that this is not the case. ${ }^{4}$

\footnotetext{
${ }^{3}$ In the same paper, Sperber (1997) also discusses reflective beliefs, which deal more with non-automatic inferences derived from actively seeking conceptual identifications from a reservoir of learned semantic concepts. An example of a reflective belief is that water is $\mathrm{H}_{2} \mathrm{O}$.

${ }^{4}$ While the function of stone play in macaques remains unknown, for instance, leafgrooming in chimpanzees has been interpreted as an attention-getting mechanism that serves to initiate or enhance conspecific grooming bouts (Plooij, 1978; Wrangham, 1980).
} 
But it is another behavior, 'rain dancing," that has captured the attention of some researchers interested in the evolutionary origins of religion (e.g., Goodall 1975; Guthrie 1993). Chimpanzees will often engage in display behavior — slow swaggering, charging, and hooting often with the aggressive throwing of nearby objects — at the start of rainstorms (Goodall 1975). Guthrie (1993) states, "My guess is that the display is indeed a threat against the storm and that the chimpanzees do perceive the storm as animate" (p. 52) and later, "if religion is anthropomorphism, then the animal analogue is zoomorphism: the attribution of animal traits to what is not animal" (p. 202). But I am afraid that Guthrie misses a crucial point with his analysis of religion as essentially anthropomorphism. If, as I argue, humans alone are able to animate inanimate events and objects with intentions, desires, and beliefs, there can be no analogue to reflective animism in the nonhuman world. And it is this breed of animism that underlies religious and otherwise spiritual attribution in modern humans. While chimpanzees may indeed be engaging in threat displays during thunderstorms, it is not apparent that they are incarnating the storm as an intentional agent. Rather, what they are likely doing is relying on the perceptual strategy of reflexive animism, in which the continued biologically relevant features of animacy accompanying the storm sudden, loud noises, shaking branches, unexpected movements of the immediate environment - render them sensitive to the hallmarks of rival chimpanzee communities or other animal predation and consequently elicit the automatic behavioral strategies used to deal with such threats. This does not involve animating the storm with mental states — something not infrequently done by humans. Compare the chimpanzee rain dance, for instance, to the serious attempts of flight navigators and sailors in "outsmarting" dangerous thunderstorms in their paths.

${ }^{5}$ Although the behavior has been termed 'rain dancing' it bears little resemblance to the ritualistic human behavior going by the same name. Among some hunter-gatherer societies, humans engage in rain dancing during times of drought, summoning supernatural intervention in order to cause the rains to fall. This is quite different from the sort of 'rain dancing' chimpanzees are doing, where the behavior is only seen immediately preceding storms - when the environment is symptomatic of their encroachment — or actually during rainfall. The difference between the two cases perhaps reflects a dependence on causal reasoning in humans and a dependence on stimuli inducement in chimpanzees. 


\section{Invisible Friends and Make-Believe Termites: Imaginative Play in Humans and Other Species}

This discussion of animism leads into another type of related behavior that presumably involves secondary representation. Piaget (1962) believed that imaginative play reflects mental representation because one object (or the absence of an object) "stands for" another, functionally distinct, object. Therefore it involves a detachment from the present perceptual environment and a substitution for a real object with the represented states of an imagined object. It is not so straightforward, however. Lillard (1993), for instance, sees imaginative play only as an understanding in young children that an object is similar to another object (e.g., a banana and a phone) and the similarity then triggers learned procedural scripts directed toward the displaced object. This model assumes that young children are just "acting if" one object is another, not that it "stands for" the other object. The disagreement, then, is between signal and symbol, an important distinction for our theistic investigation. As we will see, this cognitive differentiation accompanies the development of intentional communication.

If we are to adhere to the formal definition of symbolic representation (which I strongly suggest that we do), true symbolic play should be defined as the representation of objects, social scripts, and mental events in the absence of any perceptual eliciting stimuli while in the context of play, as is the case with imaginary friends. Imaginative play that does not involve a clear detachment from the perceptual cues of the incorporated objects, such as is the case of the banana-telephone, might more appropriately be referred to as feature-dependent make-believe. Certainly there is a continuum along which imaginative play behaviors vary in terms of the degree of perceptual matching between enlisted objects and play scripts, but the greater the propositional distance between the two, the more likely that the symbolic capacity is engaged. The child using a rock to simulate the transatlantic flight of an aircraft over a small puddle serving as the ocean might be involved in a wholly different cognitive activity from the child dressing her dolls.

While the imaginative play of very young children between 18-24 months of age frequently involves objects that are physically similar to the represented objects, this is not so with slightly older children (Ungerer 
et al. 1981). Beginning at around 34 months, children's imaginative play begins to clearly involve representations of objects that bear little perceptual resemblance to the objects used. The ontogenetic change has been described as "... a decrease in dependence on both strong perceptual support and action for the definition and expression of the symbolic relation" (Ungerer et al. 1981, p. 194). Certainly by the time a child enters kindergarten and frequency of imaginative play peaks at about $33 \%$ of all play behaviors (Fein, 1981), it has become a complex and elaborate enterprise and even includes representation of animate beings and their associated imagined psychologies in the absence of any physical cues.

There are few cases of play behavior in chimpanzees and other species that can be taken as prima facie evidence of imaginative play, even at the rudimentary level of cued representation (i.e., feature-dependent make-believe) seen in 2-year-old humans. The only controlled laboratory experiment on imaginative play in chimpanzees revealed no evidence of the behavior (Mignault 1985). But there are some anecdotal reports that are not easily dismissed. The sign-language trained chimpanzee, Washoe, for instance, reportedly bathed, soaped, and dried her dolls (Gardner \& Gardner 1971; see also Jensvold \& Fouts 1993), and Lucy, another human-reared chimpanzee, signed to her dolls (Temerlin 1975). At least one human-reared orangutan (Miles, Mitchell \& Harper 1996), gorilla (Patterson \& Cohn 1994), and bonobo (Savage-Rumbaugh \& MacDonald 1988) have also demonstrated similar behaviors with their toys. And this category of play behavior is not unseen in the wild, either. Goodall (1986) describes how a 4-year-old female named Wunda "picked a tiny twig, perched herself on a low branch of a sapling in the same attitude as her mother, and poked her little tool down - into an imaginary nest" (p. 591). Wrangham (1995) and Matsuzawa (1995) report separate incidents of chimpanzees from the Kibale Forest in Uganda and Bossou in Guinea, respectively, treating a log and a dead branch as if it were an infant.

What is strikingly similar in all of these anecdotal reports, however, is that the objects employed in ape "symbolic play" all have perceptual qualities that are similar to the represented objects. It is not such a great leap, for instance, to go from a real human baby, which needs to eat and be treated as an animate being, to a lifelike replica. The human-reared apes are likely responding to the dolls "as if" they are 
real because the dolls' animate features trigger the appropriate procedural scripts, scripts that have been learned in the immersive context of human culture. Controlled experiments have shown that enculturated apes can, in the presence of the appropriate stimuli, draw from their long-term memory stores and reenact the motoric procedural scripts learned from watching others (Bering, Bjorklund \& Ragan 2000; Tomasello, Savage-Rumbaugh, \& Kruger 1993). Similarly, while it is more difficult to rule out observer attribution in the case of the ethological reports, the kinesthetic and haptic "feel" produced by the weight of a small log and its shape and proportions are not wholly dissimilar to those of a chimpanzee infant - and both wild juveniles had frequently observed maternal behavior in their communities (see Wrangham 1995; Matsuzawa 1995).

The wary reader will note that imaginative play in older children, too, relies to a large extent on the observable features of the props used (otherwise toy manufacturers would not spend millions of dollars on designing realistic action figures and dolls) and also on learned sociodramatic scripts. But, again, while this dependence on perceptual cues might be a prominent, even primary, mode of imaginative play in children, humans are capable of representing objects (and environments) at increasingly detached levels and do not have to rely exclusively on the observed properties of physical objects. Young children can invoke imaginary elements and apply it to an object that lacks any perceptual similarity to those representations — as when a 6-year-old uses a red marker to transform a blank piece of paper into a smiling picture of his mom.

The point is not to argue that other primates do not have representational abilities, only that such representations are directly linked to eliciting features of the currently experienced environment. To put it bluntly, they do not seem to have conscious, unconstrained access to their own representations. Surely other species are intentional agents, but without the conceptual scaffolding provided by a full understanding of the nature of symbols, their representations can never be divorced from a feature-induced view of the outside world. And there is no compelling evidence to suggest that these construals include intangibles such as mental states. While the gorilla Koko might mold her dolls' hands to make the signs for 'drink mouth' (Patterson \& Cohn 1994) she has yet to have a conversation with them 
about her heart's desires — something that any 5-year-old child is prone to do.

The perceptually bound representations involved in feature-dependent make-believe translate smoothly to the area of ape social cognition; it appears that apes rely on cued signals in both deploying and responding to social behaviors. The action itself is what is attended to, not the unobservable causes of the action. Chimpanzees seem unable, in other words, to gauge the actions of others in terms of intentional communication; rather, they rely on processes such as "ontogenetic ritualization" whereby a communicatory signal is created by two organisms shaping each other's behavior in repeated instances of a social interaction (see Tomasello 1999). For instance, aggressive postures in dominant males become signals for subordinate animals — weaker individuals come to expect the aversive aftermath of the other's display. However, the posture does not symbolize the mental state of anger boiling beneath.

Tomasello, Call, and Gluckman (1997) provided experimental evidence of chimpanzees' inability to understand the communicative intent of novel signs (but more appropriately called symbols). Testing both chimpanzees and young children, the authors attempted to convey to the subjects the hiding location of a desirable reward by: (a) pointing to the correct container, (b) placing a small wooden indicator on top of the correct container, or (c) showing them an exact replica of the correct container. The children quickly exploited all three methods of communication and readily located the rewards. The chimpanzee subjects, however, were unable to do this for any of the communicative symbols that they had not already operationally learned prior to the experiment. They interpreted the symbols, rather, not as communicative attempts but as discriminative markers - cued signs that could eventually lead to heuristics for recovery of the rewards (e.g., "pick the box with the marker on top").

The distinction between feature-dependent make-believe and true symbolic play, then, is an important one for an evolutionary model of theism - without the ontogenetic emergence of detached representations (i.e., "aboutness"), later developments in religious symbolic thought would be impossible. Dependence on cued signals might explain why children cover their ears at the first stroke of lightening in anticipation of the thunder to shortly follow, but it would not have worshippers wondering, 
for instance, what the sudden rash of deadly plagues in some part of the globe really "means." Religious individuals regularly interpret ambient natural events as the intentional communicatory acts of deities, ghosts, and ancestral spirits. It is as if the physical world serves as these non-natural agents' blackboard - messages are conveyed via the random mechanics of an otherwise existential setting. While we commonly speak of these "signs from God," what we are really referring to are the symbols that represent the intentions of a non-natural agent. Attribution theorists have found that a proximal-distal attributional model is the primary mechanism by which non-natural agency is instantiated; gods and other non-natural agents are believed to distally cause proximal naturalistic events (Lupfer et al. 1994; Weeks \& Lupfer 2000). Just as we interpret the communicative behavior of other humans in terms of their underlying mental states, religious individuals interpret the observable acts of nature in terms of the unobservable mental states of gods. Few Westerners, for instance, have ever suffered some traumatic turn of events in their lives and not attempted to figure out just exactly what God was trying to "tell" them. We could not entertain such (quite spontaneous) notions without the cognitive requirements needed for understanding others' communicatory acts as referential and intentional (i.e., symbolic).

\section{Dead Relatives and Ancestral Spirits: A Cognitive Distinction}

Developmental psychologists have long speculated about the nature of the death concept in young children (e.g., see early work by Nagy 1948). Because the concept is intertwined with the maturation of the distinction between animate and inanimate objects, research has focused on children's understanding of biological death (Slaughter, Jaakola \& Carey 1999; Speece \& Brent 1984). H. Barrett (1999) has provided convincing evidence that children as young as three years of age understand the biology of death from the vantage point of the predator-prey relationship. This adaptationist argument presupposes that a conceptual — though implicit - understanding of death stems from the selective advantages such representations would incur for "knowledgeable" individuals. He highlights three classes of death mechanisms. An avoidance mechanism would benefit the child by causing her to avoid life-threatening objects or situations, such as hazardous behavior on a fragile precipice. A detection mechanism, in contrast, 
would allow an individual to determine when an animal (or human) is dead, and thus would either evoke anxiety-reducing behavior in the case of a dead predator or cause the child to seek another prosocial relationship with a living attachment figure in the case of a dead parent. Finally, a causation mechanism would facilitate the learning of self defense and, later, hunting.

Because empirical work addressing what other animals understand about death is inherently difficult to do, animal death responses remain unobserved in controlled settings. Therefore ethological reports must for now - suffice as our only window through which to glimpse this very interesting topic. But it is a window with a good view. It shows us, among other things, that there is reason to believe that the philosophical axiom "only humans are aware of their own mortality" might in fact be incorrect, at least in the sense of implicit awareness defined by H. Barrett. Evolutionary psychology informs us that extant behaviors are those that were shaped by forces of natural selection; accordingly, most behaviors deployed by individual organisms are strategies designed to allow them to survive and reproduce (see Cosmides \& Tooby 1987). It is not surprising, then, that we find evidence of the unconscious mechanisms described above in other species; they, too, evolved in dangerous environments rife with predators and disease, form dependent attachments with conspecifics, and often play the role of predator in adulthood. ${ }^{6}$

But as they have done with nearly every other category of behavior once considered unique to humans, it is the great apes that force us to reevaluate claims that conscious awareness of death is found only in our species. Chimpanzees display some rather enigmatic behaviors around dead conspecifics, and cognitive theorists have yet to contribute seriously to the debate over just what exactly is occurring with these death responses. The primate ethologist Frans de Waal, however, has made the surprisingly strong statement, "Seeing the termination of a familiar individual's life, chimpanzees may respond emotionally as if realizing, however vaguely, what

\footnotetext{
${ }^{6}$ The avoidance mechanism seems particularly strong across a wide range of taxa. Experiments showing unconditioned fear responses of various species to the visual cliff display (Gibson 1979) and to some natural predators (e.g., Cheney \& Seyfarth 1990) document that humans are not alone in evidencing an implicit awareness of ecologically derived causes of death.
} 
death means" (1996b, p. 55, italics added). Surely the death of a conspecific with whom an animal is emotionally attached can lead to outward displays of intense grief, even bereavement (Goodall 1990). What causes these emotions, however, is not necessarily an awareness of what death "means" - but is perhaps an anxiety-laden response to the sudden and unexpected severing of the attachment relationship (see Kaufman \& Rosenblum 1967). The mother-infant bond is so strong in nonhuman primates, for instance, that the detection mechanism is seemingly overwritten by emotional attachment; females will often carry the carcasses of their deceased infants until the small body has undergone substantial decomposition.

However, in de Waal's defense, the statement refers more to the responses of chimpanzees to fallen group members than to dead offspring or mothers. He writes of one group's response to the death of a former alpha male chimpanzee severely maimed by rivals: "They were completely silent during the time that Luit's body was lying in his cage. The following morning, even at feeding time, hardly any sounds were heard. Vocal activity resumed only after the corpse had been carried out of the building" (de Waal 1996b, p. 66). And Teleki (1973) details how a group of chimpanzees at Gombe reacted to the accidental falling death of a fellow conspecific: at first there was raucous displaying and contagious fear response, followed by a period of intense quietude, careful visual inspection and overall attention directed toward the body, and finally after several hours of corpse-centered activity, the reluctant moving off of the remaining group members.

Before we can credit chimpanzees with a conscious death concept, however, we must raise our cautionary flags once again and be careful not to fall prey to the argument by analogy. That approach, as has been shown elsewhere (see Povinelli et al., 2000) is inherently flawed. Yet if we are prepared to stand up for it once again, then what are we to make of the "ceremonial" gathering of black-billed magpies in response to the sudden death of a conspecific (Miller \& Brigham 1990)? Are we willing to say that they, too, have a vague notion of what death "means"? Given what we are learning of the ostensible mindblindness of other animals, it is perhaps wiser to argue that neither chimpanzees nor black-billed magpies have the cognitive hardwiring needed to represent death as the end of personal existence. Rather, both species are probably engaging in a 
complicated behavioral response that reflects their primitive understanding of the agency of animate beings and other perceptual cues of animacy in combination with the unexpected termination of a social relationship. For reasons to follow shortly, I suggest that we screw our skeptics' caps on firmly when we read stories of Koko the signing gorilla asking her trainer where we go when we die.

Before researchers can even begin to address the issue of just how sophisticated death concepts in nonhuman species really are, a distinction must first be drawn between biological death and psychological death. Biological death is the end of bodily functioning, including the deactivation and subsequent deterioration of both interior and exterior forms and processes. In contrast, psychological death is the end of cognitive functioning, including the sudden and complete deactivation of the entire mental suite comprising cognition. ${ }^{7}$ A much-needed area of research in child development is an exploration of whether children represent death of psychological processes in a manner consistent with their seemingly precocious representation of biological death. There indeed is reason to believe that a wide conceptual gap exists between understanding death as the mechanistic breakdown of the body as machine and understanding death as the natural finite boundary of psychological agency. Certainly most adults express confusion on the matter. Hinde (1999) notes that "[ghosts] can suffer just as if they had bodies; they can be vengeful and vindictive, or wise" (p. 71; see also Boyer 1994). This is particularly surprising in light of evidence showing that even young children have knowledge that the brain - a physical organ subject to decomposition - functions to produce cognitive activities such as thinking (Johnson \& Wellman 1982; see also Flavell 1999). Culturally endorsed defense mechanisms may play an important role in substantiating such counterintuitive beliefs. Denial of death, argues Yalom (1980), is learned through listening and observing the actions of elders. ${ }^{8}$

But perhaps such beliefs are not as counterintuitive as they might, at first blush, appear to be. Keil (1989) found that, beginning around 7 -years of age, children realize that organisms maintain their essential

\footnotetext{
${ }^{7}$ An interesting distinction between the two is that psychological death can occur without
} biological death, but (at least from a monistic standpoint) the reverse is not true.

${ }^{8}$ Statistics certainly back this up. Hood et al. (1996) reported that just under $80 \%$ of adult Americans believe in some form of an after-life. 
identity over (often quite dramatic) morphological transformations, but understand that artifacts do not possess the unobservable essences that resist type permutation. Although the empirical literature has not yet dealt specifically with the question of whether essences survive biological death, people appear to reason from a fairly early age that species essences survive undiminished when they are transferred via biological reproduction - transference of essence to a wholly different individual form. Such reasoning might be viewed as a stepping-stone for later developments in after-life representations. When applied to the unobservable properties of mind, essentialism is a cognitive process that provides an eerily plausible explanation for the pan-cultural maintenance of personal essence (e.g., aggregation of intangibles such as personality and self-awareness) after physical death (for a related argument see Elkind 1979). For humans, a species able to represent them, mental states are real constructs. Like helium captured by a balloon that ultimately leaks unseen from of its physical vessel into the atmosphere, so too is the personal essence of a human envisioned to "leave" the brain upon biological death. In order to preserve cognitive equilibrium in the domain of folk physics, people seem to believe that this essence must similarly "go somewhere." There is experimental evidence to support this line of reasoning. Au, Sidle, and Rollins (1993) showed that even very young children appeal to invisible particles in explaining how a substance (e.g., sugar cube) can continue to exist despite its visual disappearance (e.g., dissolved in water).

In this vein, dependence on prospects of never-ending life might lie more in our inability to represent non-states than in our inability to emotionally cope with our own mortality. Because it is impossible to represent "nothingness" as a pure vacuum state (Flavell, Green \& Flavell 1995), humans run into serious difficulties in trying to conceive of a personal nonexistence. From a theoretical stance, we understand that an unconscious individual cannot be aware of anything. But from an epistemological position, the distinction between consciousness and unconsciousness is a bit more abstruse; by definition, we can never truly experience unconscious states, but can only look back upon the continuous expanse of our ideations and recognize a break in the flow of our consciousness, as in the case of non-REM sleep. We cannot know psychological death at all, however, as it permanently stops this 
flow and therefore precludes us from reflecting back upon a state of lost cognition. William James' stream of consciousness, as it were, is not just temporarily stilled — it dries up. Similarly, because we have not experienced permanent brain death ourselves, we cannot effectively simulate the state of nonexistence of psychologically dead others (see Harris 1992 for a discussion on simulation theory). Only the most distant, fully detached logic can battle such cognitive constraints - and even then, I would argue, logic is only partially successful at the task. In short, people seem predisposed to believe in life after death because their natural cognition mandates such beliefs.

This does not, however, minimalize in any way the impact of cultural or subcultural influences on the formation of richer ideas about the afterlife; but the central question to be asked is why each cognitively normal adult has a theory (if we were to ask them) of what will happen to them when they die. The answer, I believe, is that humans' metarepresentational capacity drives them to reason about the contents of their own constrained cognitions. Theories are thus borne out of adherence to, adjustment to, or rejection of these natural cognitions. Religious institutions and, indeed, rationalist and empiricist philosophies only capitalize on these theoretical drives. Core, intuitive after-life beliefs come to be pirated by a metarepresentational system that allows for theoretical views about the destination of individual consciousness following biological death, with such views being influenced by both social and individual factors. The myriad theoretical views in question are virtually incalculable, ranging from postulating a cyclic rebirthing process, as in the Buddhist and Hindu religions, to a complete rejection of psychological continuity following biological death, an intrinsic (if not much discussed) tenet of scientific materialism. However, these theoretical views occur precisely because human organisms, from a very young age, have the unique capacity to represent their own natural beliefs about the world - core psychological structures with real cognitive constraints. The theories are merely reactions in support of (in the case of psychological continuity theories) or against (in the case of psychological discontinuity theories) such intuitive beliefs. Surely the volatile struggle between an analytical understanding of biological death as the end of physical - and hence brain - functioning and a motivational component behind maintaining the self seems to have led to eons of both 
rationalist and romantic conjectures of what becomes of the man once he has been laid in his grave.

Without postulating, as others have done (e.g., Spencer 1898), that the origins of theism stem directly from the worship of deceased ancestors, a number of parallels can be seen between the type of representations involved with after-life beliefs and those of god concepts. Both involve the intuitive attribution of psychological agency to non-natural "beings." Both gods and ghosts serve as potentially communicative social partners, acting as the perceived recipients of declarative information and the purveyors of such information. And finally, both involve essentialist categories that might not be subject to biological death. Drawing from the mounting body of evidence showing that other primates cannot represent mental states like beliefs, knowledge, and intentions, we seem to be on rather firm footing by speculating that they cannot hold any notions concerning psychological death. Where chimpanzees seem confined to seeing "dead relatives," therefore, humans can, in addition to this, see "ancestral spirits."

\section{Concluding Remarks}

Because the worshipper-deity relationship is a highly social one, theistic representations necessarily demand that the worshipper possess the social cognitive skills allowing him to perceive others as intentional agents. Both young children and other primates show a rudimentary and implicit awareness of the natural causes of motion in both animate and inanimate objects when presented with counterintuitive demonstrations (Gergely 1995; Golinkoff \& Harding 1980; Hauser 1998) and have some understanding of biological features and properties (Keil 1979; 1989; Brown \& Boysen, in press). However, I argued that a closer analysis reveals that humans, unlike great apes, might represent the distinction between animate and inanimate objects at increasingly sophisticated levels of awareness, attributing not only directed agency to living kinds but also higher-order intentions, desires, and beliefs.

The representational abilities underlying true symbolic play were deemed important for experiencing theistic percepts because without an understanding of the function of symbols, religious individuals would not be able to interpret an otherwise existential existence as meaningful. Researchers are able to disambiguate imaginative play based on an "as 
if" (perceptually triggered representation) mode of operation from that involving a "stands for" (detached representation) category in children at about 34 months of age (Ungerer et al. 1981). Most of the anecdotal reports of imaginative play in great apes are ambiguous and those that are convincing involve objects that have some perceptually similar features to the represented objects (e.g., Gardner \& Gardner 1971; Temerlin 1975; Goodall 1986).

Since both after-life representations and the god concept involve the same types of intuitive cognitive constructs, the ability to have notions of (and refute) psychological death was viewed as closely related to experiencing theistic percepts. Although there is no empirical work from which we can draw in order to have a more informed opinion on the nature of death concepts of other species, I argued that it was likely, given what we know of their seeming inability to impute mental states, that their understanding is limited to an implicit awareness of biological death.

I caution that the arguments presented in the current article must remain only tentative until further evidence rejects (or confirms) theory of mind in great apes and the role of higher-order cognitions in religion becomes increasingly known. There are several directions that researchers can take to begin to address these issues, on both the human and nonhuman primate fronts. For example, to my knowledge there has been no attempt, either formal or informal, to investigate the religious cognition of high-functioning autists or individuals with Asperger syndrome. Because previous research (see Baron-Cohen, Tager-Flusberg \& Cohen 1993) has shown that these disorders might involve impairments in the specific module that the current article has attempted to highlight as the key to religious cognition, structured interviews with these individuals on their religious concepts and attribution styles might prove to be especially valuable. Also, in addition to exploring what young children know about the biological correlates of death, cognitive developmentalists should turn to the question of how children of varying ages reason about the psychological correlates of death, and at what ages conceptual changes take place. In addition to asking an open-ended question such as, "After someone has died, does he still need food?" we should begin to ask children, "After someone has died, does he wish he was still alive?" with every attempt to unconfound the effects of learned input from natural concepts being 
made. If done correctly such an approach could go far in helping cognitive scientists understand the biological bases of after-life beliefs. Research on the cognitive components underlying primate communication must begin to carefully control for behavioral learning, as some studies have already done. Perhaps a shift in emphasis from direct species-specific modes of communication, such as gestures and vocalizations, to more indirect means of communication, such as the inferential processes underlying footprint tracking, should take place. In addition to being easier to disentangle from behaviorist learning processes, the latter category, it would seem, more closely approximates the form of cognition involved in religious attributions. The more divorced the means of communication from the present perceptual environment, the more likely that the conceptual reasoning draws from the same pool of cognitive resources involved in religious cognition, where proximal naturalistic events are explained by postulating distal non-natural causation. Also, researchers might explore what chimpanzees understand about natural categories, and specifically whether they have distinct categories for animate beings versus inanimate objects, and whether those categories have permeable boundaries. For instance, would chimpanzees' expectancies be violated if they saw a stick being treated as if it were alive? And, similarly, would they be surprised if they saw an experimenter treating an ostensibly live mouse as if it were a tool? How would their responses to these events differ from those of young children's?

In conclusion, little is known about how chimpanzees represent the agents, objects, and events populating their natural environments, and even less is known about how the other great apes do so. In light of what we do know, however, it seems safe to assert with some degree of confidence that only humans possess the cognitive structure necessary for experiencing theistic percepts. Other species seem not to be reasoning about the mental states of their own kind, let alone the disembodied minds of gods and other non-natural agents. Although we are of course obligated to grant him poetic liberty, the Swiss dramatist Friedrich Dürrenmatt (1952) was seemingly wrong when he wrote, "God is an inhuman concept." It may be primitive, but it appears as if it is nothing but human. 


\section{REFERENCES}

AU, T.K. \& Romo, L.F.

1999 Mechanical causality in children's "folkbiology." In D. Medin and S. Atran (Eds), Folkbiology, pp. 355-401. Cambridge, MA: MIT Press.

Au, T., Sidle, A. \& Rollins, K.

1993 Developing an intuitive understanding of conservation and contamination: Invisible particles as a plausible mechanism. Developmental Psychology 29, 286-298.

BARON-COHEN, S.

1999 The evolution of a theory of mind. In M.C. Corballis and S.E.G. Lea (Eds), The descent of mind: Psychological perspectives on hominid evolution (pp. 261-277). New York: Oxford University Press.

Baron-Gohen, S., Tager-Flusberg, H. \& Cohen, D.

1993 Understanding other minds. Oxford: Oxford University Press.

BARRETT, H.C.

1999 Human cognitive adaptations to predators and prey. Doctoral Dissertation, Dept. of Anthropology, University of California, Santa Barbara.

BARRETT, J.L.

2000 Exploring the natural foundations of religion. Trends in Cognitive Science 4, 29-34.

BARRETT, J.L. \& KeIL, F.C.

1996 Anthropomorphism and God concepts: Conceptualizing a non-natural entity. Cognitive Psychology 3, 219-247.

Bering, J.M., BJorklund, D.F. \& Ragan, P.

2000 Deferred imitation of object-related actions in human-reared, juvenile great apes. Developmental Psychobiology 36, 218-232.

Boesch, C.

1991 Teaching among wild chimpanzees. Animal Behavior 41, 530-532.

BOYER, P.

1994 The naturalness of religious ideas: A cognitive theory of religion. Berkeley, CA: University of California

Press.

1999 Functional origins of religious concepts: Ontological and strategic selection in evolved minds. Paper presented for the Malinowski Memorial Lecture, London, UK.

BROWN, D.A. \& BOysen, S.T.

2000 Spontaneous discrimination of natural stimuli by chimpanzees (Pan troglodytes). Fournal of Comparative Psychology 114, 392-400.

BURKERT, W.

1996 Creation of the sacred. Cambridge, MA: Harvard University Press.

Byrne, R. \& Whiten, A.

1990 Tactical deception in primates: The 1990 database. Primate Report 27, 1-101.

Call, J. \& Tomasello, M.

1994 The production and comprehension of referential pointing by orangutans (Pongo pygmaeus). Fournal of Comparative Psychology, 108, 307-317. 
Cheney, D.L. \& Seyfarth, R.M.

1990 How monkeys see the world. Chicago: University of Chicago Press.

Cosmides, L. \& Tоовy, J.

1987 From evolution to behavior: Evolutionary psychology as the missing link. In

J. Dupre (Ed.), The latest on the best: Essays on evolution and optimality, pp. 277-306.

Cambridge, MA: MIT Press.

DENNis, W.

1953 Animistic thinking among college and university students. The Scientific Monthly 76, 247-249.

DÜrRENMATT, F.

1952 Die Ehe des Herrn Mississippi/The Marriage of Mr. Mississippi (play).

ELKIND, D.

1979 The child and society. New York: Oxford University Press.

FEIN, G.

1981 Pretend play: An integrative review. Child Development 52, 1095-1118.

FLAVELL, J.H.

1999 Cognitive Development: Children's knowledge about the mind. Annual Review of Psychology 50, 21-45.

Flavell, J.H., Green, F.L. \& Flavell, E.R.

1995 Young children's knowledge about thinking. Monographs of the Society for Research in Child Development 60, 1.

FREUD, S.

1964 (1927) The future of an illusion. Garden City: Anchor Books.

GalluP, G.G.

1970 Chimpanzees: Self-recognition. Science 167, 86-87.

GARDNER, B.T. \& GARDNER, R.A.

1971 Two-way communication with an infant chimpanzee. In A.M. Schrier and F. Stollnitz (Eds), Behavior of nonhuman primates, vol. 4, pp. 117-185.

Gergely, G., Nádasdy, Z., Cisibra, G. \& Biró, S.

1995 Taking the intentional stance at 12 months of age. Cognition 56, 165-193.

GiBson, J.J.

1979 The ecological approach to visual perception. Boston: Houghton Mifflin.

GolinkofF, R. \& HARding, G.

1980 Infants' expectations of the movement potential of inanimate objects. Paper presented at the International Conference on Infant Studies, New Haven, Connecticut.

Gómez, J.C. \& Teixidor, P.

1992 Theory of mind in an orangutan: A nonverbal test of false-belief appreciation. Paper presented at the XIV Congress of the International Primatological Society, Strasbourg.

GOODALL, J.

1975 “The chimpanzee." In V. Goodall (Ed.), The Quest for Man, pp. 131-170. New York: Praeger. 
1986 The chimpanzees of Gombe. Patterns of behavior. Cambridge, MA: Harvard University Press.

1990 Through a window. Boston: Houghton Mifflin.

Gopnik, A. \& Meltzoff, A.

1997 Words, thoughts, and theories. Cambridge, MA: Bradford Books/MIT Press. GRANDIN, T.

1995 Thinking in pictures: And other reports from my life with autism. New York: Doubleday. Guthrie, S.

1993 Faces in the clouds: A new theory of religion. New York: Oxford University Press.

Hare, B., Call, J., Agnetta, B. \& Tomasello, M.

2000 Chimpanzees know what conspecifics do and do not see. Animal Behaviour 59, 771-785.

HARRIS, P.L.

1992 From simulation to folk psychology: The case for development. Mind and Language 7, 120-44.

HAuser, M.

1998 Expectations about object motion and destination: Experiments with a nonhuman primate. Developmental Science 1, 31-38.

HINDE, R.A.

1999 Why gods persist: A scientific approach to religion. London: Routledge.

Hood, R.W., Spilka, B., Hunsberger, B. \& Gorusch, R.

1996 The psychology of religion. New York: Guildford.

HufFMan, M.A.

1984 Stone-play of Macaca fuscata in Arahiyama B troop: Transmission of a nonadaptive behavior. Fournal of Human Evolution 13, 725-735.

INAGAKI, K. \& HATANO, G.

1987 Young children's spontaneous personification as analogy. Child Development 58, 1013-1020.

Jensvold, M.L.A. \& Fouts, R.

1993 Imaginary play in chimpanzees (Pan troglodytes). Human Evolution 8, 217-227.

JOHnson, S. \& CAREY, S.

1998 Knowledge enrichment and conceptual change in folk biology: Evidence from people with Williams syndrome. Cognitive Psychology 37, 156-200.

Johnson, G.N. \& Wellman, H.M.

1982 Children's developing conceptions of the mind and brain. Child Development 53, 222-234.

Kaufman, I.C. \& Rosenblum, L.A.

1967 Depression in infant monkeys separated from their mothers. Science 155, 1030-31. KEIL, F.

1979 Semantic and conceptual development: An ontological perspective. Cambridge, MA: Harvard University Press.

1989 Concepts, kinds, and cognitive development. Cambridge, MA: MIT Press. 
Lawson, E.T. \& MCGauley, R.N.

1990 Rethinking religion: Connecting religion and culture. Cambridge: Cambridge University Press.

LILLARD, A.S.

1993 Young children's conceptualization of pretense: Action or mental representational state? Child Development 64, 372-386.

Lupfer, M.B., DePaola, S.J., Brock, K.F. \& Clement, L.

1994 Making secular and religious attributions: The availability hypothesis revisited. Fournal for the Scientific Study of Religion 33, 162-171.

Lupfer, M.B., TOlliver, D. \& JaGKSOn, M.

1996 Explaining life-altering occurrences: A test of the 'God-of-the-gaps' hypothesis. Fournal for the Scientific Study of Religion 35, 379-391.

Maser, J.D. \& Gallup, G.G.

1990 Theism as a by-product of natural selection. Fournal of Religion 90, 515-532.

Matsuzawa, T.

1995 Chimpanzee being (excerpt, T. Matsuzawa, Trans.). Tokyo: Iwanami-shoten.

MENZEL, E.W., Jr.

1974 A group of young chimpanzees in a one-acre field. In A. Schrier and F. Stollnitz

(Eds), Behavior of non-human primates: Modern research trends, pp. 83-153. New York:

Academic Press.

Mignault, C.

1985 Transition between sensorimotor and symbolic activities in nursery-reared chimpanzees (Pan troglodytes). Fournal of Human Evolution 14, 747-758.

Miles, H.L. Mitchell, R.W. \& Harper, S.E.

1996 Simon says: The development of imitation in an enculturated orangutan. In A.E. Russon, K.A. Bard and S.T. Parker (Eds), Reaching into thought: The minds of the great apes, pp. 521-562. Cambridge: Cambridge University Press.

Miller, W.R. \& BRigham, R.M.

1990 "Ceremonial" gathering of black-billed magpies (Pica pica) after the sudden death of a conspecific. Murrelet 69, 78-79.

Mitchell, R.W.

1993 Mental models of mirror-self-recognition: Two theories. New Ideas in Psychology $11,295-325$.

NAGY, M.H.

1948 The child's theories concerning death. Fournal of Genetic Psychology 73, 3-27.

Patterson, F.G.P. \& COHn, R.H.

1994 Self-recognition and awareness in lowland gorillas. In S.T. Parker, R.W. Mitchell and Boccia, M. (Eds), Self-awareness in animals and humans. Developmetal perspectives, pp. 273-290. Cambridge: Cambridge University Press.

Piaget, J.

1929 The child's conception of the world. London: Routledge and Kegan Paul.

1962 Play, dreams, and imitation in childhood. New York: Norton. 
PloOiJ, F.X.

1978 Some basic traits of language in wild chimpanzees? In A. Lock (Ed.), Action, gesture, and symbol: The emergence of language, pp. 111-131. London: Academic Press. Povinelli, D.J., Bering, J. \& Giambrone, S.

2000 Toward a science of other minds: Escaping the argument by analogy. Cognitive Science 24, 509-541.

(in press) Chimpanzee 'pointing': Another error of the argument by analogy? In S. Kita (Ed.), Pointing: Where language, culture, and cognition meet. Lawrence Erlbaum $\&$ Associates.

Povinelli, D.J. \& EDdy, T.J.

1996 What young chimpanzees know about seeing. Monographs of the Society for Research in Child Development 61, 3.

Povinelli, D.J., Nelson, K.E. \& Boysen, S.T.

1990 Inferences about guessing and knowing by chimpanzees (Pan troglodytes). Fournal of Comparative Psychology 104, 203-210.

Povinelli, D.J. \& Preuss, T.

1995 Theory of mind: Evolutionary history of a cognitive specialization. Trends in Neurosciences 18, 418-424.

Povinelli, D.J., Reaux, J.E., Bierschwale, D.T., Allain, A.D. \& Simon, B.B.

1997 Exploitation of pointing as a referential gesture in young children, but not adolescent chimpanzees. Cognitive Development 12, 423-461.

ROMANES, G.J.

1883 Mental evolution in animals. London: Kegan, Paul Trench.

Savage-Rumbaugh, S. \& MaGDonald, K.

1988 Deception and social manipulation in symbol-using apes. In R. Byrne and A. Whiten (Eds), Machiavellian intelligence: Social expertise and the evolution of intellect in monkeys, apes, and humans, pp. 224-237. Oxford: Oxford University Press.

Slaughter, V. JaAk ola, K. \& Carey, S.

1999 Constructing a coherent theory: Children's biological understanding of life and death. In M. Siegal \& C. Peterson (Eds), Children's understanding of biology, health, and ethics, pp. 71-96. Cambridge: Cambridge University Press.

SPEECE, M. \& BRENT, S.

1984 Children's understanding of death: A review of three components of a death concept. Child Development 55, 1671-1686.

SPENCER, H.

1898 The principles of sociology. New York: D. Appleton \& Co.

SPERBER, D.

1997 Intuitive and reflective beliefs. Mind and Language 12, 67-83.

SzASZ, T.

1973 The second sin. Garden City, NY: Anchor Press.

TELEKI, G.

1973 Group responses to the accidental death of a chimpanzee in Gombe National Park, Tanzania. Folia Primatologica 20, 81-94. 
TEMERLIN, M.K.

1975 Lucy: Growing up human. London: Souvenir Press.

Tomasello, M.

1999 The cultural origins of human cognition. Cambridge, MA: Harvard University Press.

Tomasello, M., Call, J. \& Gluckman, A.

1997 The comprehension of novel communicative signs by apes and human children.

Child Development 68, 1067-1081.

Tomasello, M., Savage-Rumbaugh, E.S. \& Kruger, A.C.

1993 Imitative learning of actions on objects by children, chimpanzees, and enculturated chimpanzees. Child Development 64, 1688-1705.

Ungerer, J.A., Zelazo, P.R., Kearsley, R.B. \& O’Leary, K.

1981 Developmental changes in the representation of objects in symbolic play from 18 to 34 months of age. Child Development 52, 186-195.

DE WAAL, F.

1996a Good natured: The origins of right and wrong in humans and other animals. Cambridge, MA: Harvard University Press.

1996b Peacemaking among primates. Cambridge, MA: Harvard University Press.

WEEKS, M. \& LUPFER, M.B.

2000 Religious attributions and proximity of influence: An investigation of direct interventions and distal explanations. Fournal for the Scientific Study of Religion 39, 348-362.

Whiten, A., Goodall, J., Magrew, W.G., Nishida, T., Reynolds, V., Sugiyama, Y., Tutin, C.E.G., Wrangham, R.W. \& Boesch, C.

1999 Cultures in chimpanzees. Nature 399, 682-685.

WRANGHAM, R.W.

1980 Leaf-grooming by chimpanzees: a preliminary analysis. Unpublished manuscript. WRANGHAM, R.

1995 Ape cultures and missing links. Symbols: The Peabody Museum and the Harvard University (Spring 1995), 2-20.

YALOM, J.

1980 Existential psychotherapy. New York: Basic Books. 